\title{
INFÂNCIA E ESCOLARIZAÇÃO: UM ESTUDO A PARTIR DO PROCESSO CIVILIZATÓRIO EM NORBERT ELIAS
}

\section{CHILDHOOD AND SCHOOLING: A STUDY FROM THE PROCESS CIVILIZATION IN NORBERT ELIAS}

\author{
Maurício Bueno da Rosa ${ }^{1}$ \\ Universidade Federal de Santa Catarina, SC, Brasil
}

\begin{abstract}
Resumo: Temos como objetivo contextualizar o papel da infância e da escolarização no contexto do processo civilizador. Sabendo então da importância da infância para o desenvolvimento do indivíduo bem como das potencialidades da escolarização pretendemos abordar tais temáticas do ponto de vista da sociologia e das contribuições de Norbert Elias, autor que, no corpo de sua obra, apresentou elementos para uma "sociologia da infância" que embora tenha sido pouco explorada por ele próprio ao longo de sua trajetória intelectual é motivo de discussão e desenvolvimento sistemático na atualidade. O presente artigo pretende problematizar a questão da infância e o processo de escolarização, pois Elias tratou da formação do indivíduo, a partir da organização dos grupos sociais e a constituição do processo civilizatório, tema este que julgamos ser possível compreender a partir da relação entre infância e escolarização.
\end{abstract}

Palavras-chave: Infância; Escolarização; Processo civilizador; Norbert Elias.

\begin{abstract}
We aim to contextualize the role of childhood and schooling in the context of the civilizing process. Knowing then the importance of childhood for the development of the individual as well as the potential of schooling, we intend to address these themes from the point of view of sociology and the contributions of Norbert Elias, an author who, in the body of his work, presented elements for a " sociology of childhood "which, although it has been little explored by himself throughout his intellectual trajectory, is the subject of discussion and systematic development today. The present article intends to problematize the issue of childhood and the schooling process, since Elias dealt with the formation of the individual, based on the organization of social groups and the constitution of the civilizing process, a theme that we believe it is possible to understand from the relationship between childhood and schooling.
\end{abstract}

Keywords: Childhood; Schooling; Civilizing process; Norbert Elias.

\section{INTRODUÇÃO}

A partir da noção de processo civilizador de Norbert Elias, temos como pressuposto que a infância é uma construção histórica definida pela condição social de ser criança, e não um fato natural, com isso buscamos compreender o surgimento desta e dos modos como as relações entre adultos e crianças se estabeleceram. A infância é um curto período de tempo em que a criança deverá aprender aquilo que a sociedade levou séculos para internalizar. Desse modo, a civilização das crianças é a sua educação para autorregulação que deve se realizar na escola.

Tendo isso em vista, vislumbramos que o interesse em estudar a infância, as crianças e suas relações com os demais grupos sociais não está isolado da sociedade em geral, visto que nos

\footnotetext{
${ }^{1}$ Doutor em Educação pela Universidade Federal de Santa Catarina (UFSC), coordenador de atividades de ensino da Secretaria de Educação. E-MAIL: mauriciobueno7@hotmail.com. ORCID: http://orcid.org/0000-0003-1407-357X. Revista Tópicos Educacionais, Pernambuco, v. 27, n.01, p. 210-219, 2021. ISSN: 2448-0215. https://periodicos.ufpe.br/revistas/topicoseducacionais/index DOI: 10.51359/2448-0215.2021.249565
} 
últimos anos temos assistido à emergência de um grande debate sobre as crianças e a infância, demonstrado pelas inúmeras discussões a seu respeito na mídia, assim como nas diversas ciências que passaram a conceituá-la. Norbert Elias passou toda a vida buscando entender a sociedade e o indivíduo e soube como nenhum outro atribuir ao homem e ao humano a responsabilidade pelo seu processo de individualização. Este autor apresenta a formação dos grupos sociais como lugar central e espaço construído unicamente por indivíduos, pessoas que estão continuamente se relacionando em movimentos de dependência e interdependência. Para o autor, "os seres humanos são parte de uma ordem natural e de uma ordem social" (ELIAS, 1994. p. 41) que foi sendo construída ao longo de um processo de civilização, o qual também é histórico, ou seja, "a história é sempre história de uma sociedade, mas, sem a menor dúvida, de uma sociedade de indivíduos" (ELIAS, 1994, p. 45) composta por uma infância em constante processo de transformação.

\section{METODOLOGIA}

Utilizamos como procedimento metodológico a abordagem da pesquisa qualitativa de caráter descritivo bibliográfico procurando fundamentar-se nos textos de Norbert Elias e comentadores reconhecidos por sua rigorosidade conceitual.

Seguiremos uma linha argumentativa quanto aos conceitos trabalhados, utilizando ferramentas metodológicas interpretativas, abordando aspectos sociológicos e filosóficos do processo civilizatório e seu alcance quanto a concepção de infância em Norbert Elias.

\section{EDUCAÇÃO E PROCESSO CIVILIZATÓRIO}

As crianças antes de meados do século XIX eram consideradas "adultos em miniatura" e não havia diferença no tratamento ou comportamento entre adultos e crianças. Segundo Elias, no século XIX, as pessoas incutiam novos métodos, de adultos a crianças, através do discurso oral, repetição de comportamento e implantação de novas sensações. No entanto, a socialização modificou-se aos poucos, pois os adultos passaram por séculos de mudanças lentas e conscientes e, com uma doutrinação rápida e silenciosa, tornaram-se parte da vida das crianças desde tenra idade. Na sociedade moderna, a socialização da maioria das crianças instiga e suprime automaticamente um sentimento básico de controle das emoções pessoais.

Mas esse não é o único sentimento, porque a infância é um universo de emoções diversas, a integração dessas emoções contribui para a formação de adultos, a infância é um período de transição em que as crianças estão em processo de desenvolvimento, mas vale lembrar que o Revista Tópicos Educacionais, Pernambuco, v. 27, n.01, p. 210-219, 2021. ISSN: 2448-0215. 
objetivo final inclui a maturidade na idade adulta, pode-se ver que esse conceito de infância está relacionado a uma explicação biológica. Elias (1999, p. 18) que se opôs a essa análise porque afirmou que a sociologia ainda está impregnada dos conceitos e métodos da ciência natural, necessários para liberá-la afirmou que ainda é excessivamente transferida para os seres humanos a interpretação dos fenômenos sociais.

Com base na hipótese de individualização ou composição pessoal do sujeito, nesse caso, a criança, Elias (1994) nos direciona para uma compreensão do papel decisivo das características civilizadas da escola na formação da infância. Essa visão busca estabelecer ou reconstruir crianças e escolas, suas relações sociais, sua imagem e reprodução da vida e cultura da família com grupos sociais. O interessante é que, para Elias (2012), a infância envolve um longo processo, que ainda está em andamento, entre os quais a infância é o resultado do processo de civilização e a escola é o espaço básico para a história e a construção cultural. Para o autor, as crianças não são micro adultos, "eles se tornam adultos através de processos sociais civilizados, e esses processos diferem de acordo com o desenvolvimento de seus respectivos modelos sociais civilizados" (ELIAS, 2012, p. 35). Portanto, para o autor, a civilização infantil é sua educação para a auto regulação.

Elias escreveu que lidar com o aumento do conhecimento infantil não é suficiente para analisar mudanças recentes na relação entre adultos e crianças. Para ele, essa mudança se deve ao reconhecimento das pessoas da particularidade e inovação de certas coisas, que podem estar relacionadas à “[...] necessidade que têm as crianças de viver sua própria vida, uma maneira de viver que em muitos sentidos é distinta do modo de vida dos adultos, não obstante sua interdependência com eles" (ELIAS, 2012, p. 410). O autor insiste que encontrar crianças significa, em última análise, alcançar sua relativa autonomia. Em outras palavras, deve-se descobrir que as crianças são adultos no processo de civilização social que mudam de acordo com o estágio de desenvolvimento do processo de civilização social. Em essência, o reflexo mais profundo das necessidades especiais das crianças é o reconhecimento de que elas têm o direito de serem entendidas e apreciadas com sua própria personalidade, sendo que este também é um direito humano. (ELIAS, 2012, p. 39)

Em A Civilização dos pais, Elias (2012) fez importantes contribuições ao campo da educação, reestruturando o processo civilizatório do relacionamento entre pais e filhos na maioria dos países industrializados, e enfatizou a relação de poder entre adultos e crianças. Usando "amostras de evidências" para estudar a educação das crianças, o autor concluiu que isso formará o sentimento mais humanizado da história da civilização-infância, portanto, a infância é um tempo Revista Tópicos Educacionais, Pernambuco, v. 27, n.01, p. 210-219, 2021. ISSN: 2448-0215. https://periodicos.ufpe.br/revistas/topicoseducacionais/index DOI: 10.51359/2448-0215.2021.249565 
em si, geralmente sem relógio e irracional, período em que as pessoas vivem sem grandes preocupações. No entanto, para os adulto, a infância é um período de desenvolvimento e um período de preparação para a vida futura, a sociedade frequentemente associa essa ideia às instituições escolares. Portanto, a escola será um período de crescimento, um local adequado para as crianças crescerem, onde ele se preparará para a vida adulta. Segundo Norbert Elias (1998), devido aos dois tempos inter-relacionados, infância e escola também serão construção cultural, com forte força coercitiva, que por sua vez ajudará a formar hábitos sociais e a construir de costumes.

Nesse sentido, observamos que esse paradigma tornou inviável qualquer tentativa de tratar a infância como um período ativo na dinâmica social, pois ao considerar a infância como um período vazio que apenas reproduz os valores e crenças transmitidos pela geração adulta, a análise da socialização focaliza as instituições responsáveis por esse processo: família, escola e religião, para que a infância permaneça no discurso da sociologia a margem e reforça a antiga dicotomia entre indivíduos e sociedade e entre agência e estrutura.

Essa tendência de explicar os fenômenos sociais a partir do conceito de ciência natural é objeto da crítica de Elias (1999), que ele chama de pensamento pré-científico. Portanto, para superar a dicotomia estabelecida na sociologia, Elias advogou maior autonomia conceitual nesse campo, afirmando a necessidade de estabelecer novos conceitos para que a sociologia não limite sua análise ao direito científico. Com isso, no processo de civilização infantil, a escola era considerada um local privilegiado da infância por Elias, onde as crianças tinham que aprender a sociedade em pouco tempo e passavam centenas de anos para serem internalizadas. Dessa forma, todo o grupo social precisa garantir que, dentro de um curto período de tempo (dentro de dez anos), os indivíduos se movessem na direção de se conformarem com o controle do aprendizado necessário. Portanto, "suas vidas intuitivas devem ser rapidamente controladas por modelos específicos, para que nossa sociedade tenha características próprias e se forme num processo lento de vários séculos" (ELIAS, 1994, p.145).

Afinal, na institucionalização das crianças, a escola é onde elas internalizam suas necessidades de controle interno e autocontrole como uma maneira de ser. Portanto, percebemos que a escola deve ser um espaço para reflexão, discussão, debate e questionamento. Nesse sentido, a visão do "processo de civilização" apresentada por Elias (1993) mostra que a organização e a disseminação das escolas sempre criaram uma nova condição para as crianças, agora as crianças são vistas como membros diferentes da geração adulta. Com isso, começou a constituir uma Revista Tópicos Educacionais, Pernambuco, v. 27, n.01, p. 210-219, 2021. ISSN: 2448-0215. https://periodicos.ufpe.br/revistas/topicoseducacionais/index DOI: 10.51359/2448-0215.2021.249565 
infância civilizada onde a escola é um ambiente socializado no qual podemos ser educados ou viver uma vida civilizada para nos adaptarmos à vida social. (ELIAS, 2008)

Com base no trabalho de Elias, podemos considerar o processo escolar e educacional como o processo social e político necessário para a formação de disciplinas relacionadas à estrutura social, que constituem a ordem civilizada da sociedade. Nessa perspectiva, a estrutura da psicologia humana, a estrutura da sociedade humana, a estrutura da história humana e a estrutura de conhecimento sistematicamente construída ao longo da história fazem parte do processo de educação pessoal.

No processo educacional no ambiente escolar, as crianças internalizam o conhecimento e as regras para se adaptarem aos hábitos sociais, isso corresponde à visão de Elias: todos são parentes e o estabelecimento disso parece estar na escola, onde há a relação de ensino na qual o comportamento gerado pela representação de professores e alunos constitui as relações sociais e a forma na escola.

Elias (2009) acredita que aprender é o processo que um indivíduo desenvolve em sua vida, considerando também a quantidade total de conhecimentos transmitidos pelas gerações anteriores para exercer o autocontrole. O aprendizado entre os humanos é sempre realizado em um processo vivo, um aspecto básico do desenvolvimento social, o que significa que podemos aprender mais do que outras espécies, gostar de aprender e construir tempos e símbolos dimensionais.

Entendemos que o surgimento da cultura escolar depende não apenas das ações e métodos relacionados à escola, mas também de todas as práticas e produções do período histórico, como diversas formas de expressão na arte, na literatura, na sociedade e na cultura. As obras de inúmeros intelectuais e escritores mantiveram um ideal social e cultural em sua época.

Para Elias (1998, p.111), é necessário analisar o processo de escolarização e infância juntos, pois é no espaço da criança que podemos observar a maior lei desse tempo simbólico. A subjetividade e as emoções das crianças são estruturadas de acordo com a forma como os adultos constroem seu próprio tempo. "Os indivíduos do tempo socialmente regulados quase mostram o desempenho do processo da civilização em um paradigma" (ELIAS, 1989, p. 32)

Os sociólogos acreditam que a sociedade é uma rede móvel de pessoas, que, segundo o próprio Elias, é um exemplo de falta de educação. No entanto, este exemplo nos ajuda a entender sua teoria. Para o autor, "nesta rede, muitos fios isolados são conectados entre si" (1994, p. 35). Portanto, não podemos entender a "rede" apenas olhando para um dos fios, ou mesmo para todos 
os fios juntos. "Somente a rede pode ser entendida em termos de conexão e relações mútuas. Essa conexão cria um sistema de tensão" (ELIAS, 1994, p. 40).

É esse sistema de tensão que gera o ímpeto para a mudança social. Nas palavras do autor, as crianças são como idosos, ocupando cargos e funções nessa "rede" humana. Vale lembrar que é móvel e cheia de tensão e conflito. Mesmo antes do nascimento, as crianças fazem parte da rede, porque esse é o resultado de relacionamentos entre diferentes indivíduos já é um ponto de conflito e cria um sistema tenso que promove mudanças no comportamento humano.

O comportamento mudou em relação aos outros, instintos e emoções. Segundo Elias, "quanto mais rigoroso e abrangente o controle dos instintos, inevitavelmente maior a distância entre o comportamento de crianças e adultos" (ELIAS, 1994, p. 32). Nesse sentido, é certo que, à medida que os comportamentos das crianças entre esses estágios da vida divergem, eles tendem a ter mais tempo para se preparar para as funções do adulto.

A relação estabelecida entre crianças e adultos e o significado que eles atribuem a diferentes costumes sociais são elementos da pesquisa sociológica. O desenvolvimento da educação pode ser promovido através da análise de fatores culturais e fenômenos sociais. Na época, o trabalho de Norbert Elias analisou o estabelecimento de relações interpessoais de uma maneira única, propondo uma teoria processual, que fez uma importante contribuição para o desenvolvimento da pesquisa que tenho conduzido. Essa estrutura teórica permite que as pessoas tenham uma compreensão e análise mais profundas das formas da infância na sociedade urbana e nas habilidades sociais das crianças. A teoria de Norbert Elias não é apenas digna de pesquisas aprofundadas no campo da sociologia infantil, mas também fornece referências relevantes para o campo da educação, porque aponta uma série de aspectos importantes e necessários da educação e dos processos sociais, é uma análise e contato.

Outro conceito importante proposto por Norbert Elias é o que o autor chama de "processo de civilização", que é um processo no qual o Estado-nação monopoliza a violência e a economia e é comparável ao comportamento de alto nível. A democratização gradual, ou, se quisermos, disputas entre cavaleiros e grupos armados está ocorrendo agora dentro das Cortes e do parlamento.

O ponto central no qual a teoria do processo civilizador de Norbert Elias se baseia é a existência de tais processos "cegos" (não planejados) e empiricamente comprovados. Esse é o processo de "feudalização" e / ou parlamentarização dos guerreiros medievais; na verdade, é equivalente a dizer que a violência contida no cotidiano dos guerreiros abre caminho para debater Revista Tópicos Educacionais, Pernambuco, v. 27, n.01, p. 210-219, 2021. ISSN: 2448-0215. https://periodicos.ufpe.br/revistas/topicoseducacionais/index DOI: 10.51359/2448-0215.2021.249565 
e melhorar a atitude dos cortesãos e parlamentares. Agora resolva conflitos e controle a violência de maneiras únicas relacionadas ao uso imediato e explícito da força / violência.

De guerreiros medievais que foram educados em combate a estudiosos contemporâneos que são educados em diferentes campos da ciência e da tecnologia, nosso processo de civilização desempenha um papel em diferentes níveis e, de maneira especializada, implica o trabalho da educação profissional. Norbert Elias chamou isso de um processo de monopólio do estado-nação sobre violência e economia, com comportamentos cada vez mais sofisticados e democratização gradual entre muitas classes da população, ou, se desejarmos, o processo de civilização.

De acordo com os elementos básicos determinados que caracterizam o progresso da civilização, Elias formulou a "Tríade Básica", que ilustrará o estágio de desenvolvimento da civilização:

a) $\mathrm{O}$ controle de eventos naturais, porque a ciência natural foi muito desenvolvida, porque o controle anterior de eventos não humanos foi verificado principalmente pela maior distância entre os seres humanos e os fenômenos naturais. O desenvolvimento da ciência e da tecnologia corresponde ao nível de controle humano de eventos não humanos.

b) O controle sobre o relacionamento entre as pessoas, ou seja, o controle sobre as relações sociais, é óbvio. Elias reiterou em vários parágrafos que uma característica importante da sociedade moderna é que quanto maior o escopo de suas suposições de controle sobre as relações naturais está ficando cada vez maior, e ainda está crescendo. Mais rápido que as dimensões relacionadas ao pressuposto de controlar as relações sociais. No entanto, tendo em vista as questões emocionais envolvidas no relacionamento entre as pessoas, as ciências naturais se desenvolveram mais que as ciências sociais devido a maiores dificuldades no controle das relações sociais.

c) O que um indivíduo aprende para o autocontrole em sua vida, pois não há necessidade de correr muito risco na fidelidade a Elias, acho que aqui pode afirmar o papel central da educação e da escola em sua teoria, porque o desenvolvimento do conhecimento humano sempre ocorre na forma de vida. O primeiro está em unidades simples, como famílias ou grupos, e o segundo em ambientes mais complexos, como os sistemas escolares.

Pode-se dizer que o livro "Progress of Civilization" fez importantes contribuições para aprofundar a análise genealógica da composição da infância na modernidade e a análise dos métodos educacionais das crianças. Entre os vários temas explorados por Elias, além da análise sociológica da civilização e dos conceitos culturais, a fim de entender o progresso da civilização. Revista Tópicos Educacionais, Pernambuco, v. 27, n.01, p. 210-219, 2021. ISSN: 2448-0215. https://periodicos.ufpe.br/revistas/topicoseducacionais/index DOI: $10.51359 / 2448-0215.2021 .249565$ 
Erasmo enfraqueceu os elementos da civilização, relacionados à educação das crianças e métodos educativos garantidos, Ele influenciou diretamente muitas práticas de ensino em três séculos. Segundo Elias (1993, p. 83), a tese de Erasmus é uma série de trabalhos extraordinários sobre humanismo comportamental, que constituem uma ponte entre a Idade Média e a era moderna. Esta é uma coleção de suas observações sobre a vida e a sociedade. Um aspecto interessante enfatizado por Elias $(1993$, p.84) é que o importante não é a maneira como Erasmus se refere ou à maneira apontada em outras obras humanistas, mas a maneira como elas abordam, o tom, o caminho.

Para Elias (1994, p. 31), o indivíduo existe em um relacionamento com os outros, e esse relacionamento tem uma estrutura específica para sua sociedade. Ele conseguiu sua própria marca a partir da história desses relacionamentos e dependências. Essas contribuições possibilitam afirmar que é importante considerar não apenas as diferentes maneiras de observar e interpretar a infância, mas também a aparência e o comportamento das crianças na rede de configuração social ao estudar a configuração infantil.

Os sociólogos apontam uma perspectiva analítica, ou seja, a construção histórica da diferença entre a infância e a idade adulta, vemos que pensamos sobre questões educacionais e culturais com o autor. Este é um convite para entender o processo da civilização por meio da internalização de modelos comportamentais. No entanto, Elias está falando de um processo cujo eixo básico de análise é a estrutura social. Nessa perspectiva, redes interdependentes significam que as pessoas percebem que não haverá indivíduos instruídos sem indivíduos instruídos pessoalmente, E assim como este constitui o corpo principal, eles constituem o corpo principal no movimento em que o fluxo é uma lei. Portanto, nada é óbvio, nem é completamente certo.

\section{CONSIDERAÇÕES FINAIS}

Elias acredita que a civilização deve ser entendida como um processo contínuo e inacabado. Portanto, um dos objetivos de sua teoria é analisar a formação e as mudanças da estrutura psicológica pessoal, assim, podemos apontar que a infância é um ponto chave na formação de padrões de comportamento, visando o desenvolvimento de uma sociedade civilizada. Como o autor nos disse, [...] nada mais é do que o resultado do processo de civilização, o processo de civilização pessoal de todos os jovens.

Portanto, quando Elias (1994) entendeu a formação dos indivíduos e da sociedade como algo comum, rompeu o paradigma de entender o tema como apenas o receptor de informações transmitidas pelas instituições sociais, fazendo com que as pessoas pensassem na infância. Há uma Revista Tópicos Educacionais, Pernambuco, v. 27, n.01, p. 210-219, 2021. ISSN: 2448-0215. 
nova compreensão do papel desempenhado no processo de socialização, então Elias (1994) quebrou a tradição sociológica de tender a pensar sobre a relação entre um indivíduo e a sociedade em uma dicotomia, como se o indivíduo tivesse absorvido apenas os valores e crenças da comunicação e aberto espaço para uma nova compreensão da dinâmica social. A interdependência entre o indivíduo e a sociedade e a noção do indivíduo de não ser passivo sobre o processo de socialização desempenharão um papel fundamental na construção do campo da sociologia infantil.

\section{REFERÊNCIAS}

ARIÈS, P. História social da infância e da família. Tradução de Dora Flaksman. Rio de Janeiro: LCT, 1978.

ELIAS Norbert. O processo civilizador. Uma história dos costumes. Rio de Janeiro: Zahar, 1994.

ELIAS Norbert. Introdução à Sociologia. Edições 70, Lisboa, 1999.

ELIAS, Norbert. A Civilização dos Pais. Revista Sociedade e Estado, Brasília, v.27, n. 3, p. 469493, set./dez. 2012.

ELIAS, Norbert. O processo civilizador: uma história dos costumes. Rio de Janeiro: Zahar, 1990.

ELIAS, N. O processo civilizador: formação do Estado e civilização. Trad. Ruy Jungmann. Rio de Janeiro: Jorge Zahar Editor, 1993.

ELIAS, Norbert. La Soledad de los Moribundos. México: FCE, 1989.

ELIAS, N. A civilização dos pais. Revista Sociedade e Estado. Brasília, v. 27, n. 3, p. 469-493, 2012.

ELIAS, N. A sociedade dos indivíduos. Tradução de Vera Ribeiro. Rio de Janeiro: Jorge Zahar, 1994.

ELIAS, N. Escritos e ensaios: 1. Estado, processo, opinião pública. Rio de Janeiro: Jorge Zahar, 2006

ELIAS, N. Introdução à sociologia. Tradução de Maria Luísa Ribeiro Ferreira. Lisboa: Edições 70, 2008. 
ELIAS, N. Introdução: Sociologia e história. In: ELIAS, N. (org.). A sociedade de corte. Tradução de Pedro Süssekind. Rio de Janeiro: Jorge Zahar, p. 27-60, 2001 b.

ELIAS, N. Mozart: Sociologia, de um gênio. Tradução de Sergio Goes de Paula. Rio de Janeiro: Jorge Zahar, 1995.

ELIAS, N. Norbert Elias por ele mesmo. Tradução de André Telles. Rio de Janeiro: Jorge Zahar, $2001 \mathrm{a}$.

ELIAS, N. O processo civilizador: Formação do Estado e civilização. v. II.Tradução de Ruy Jungmann. Rio de Janeiro: Jorge Zahar, 1993.

ELIAS, N. O processo civilizador: uma história dos costumes. Tradução de Ruy Jungmann. 2. ed. Rio de Janeiro: Jorge Zahar, 2011.

ELIAS, N. Os alemães. A luta pelo poder e a evolução do habitus nos séculos XIX e XX. Tradução de Álvaro Cabral. Rio de Janeiro: Jorge Zahar, 1997.

ELIAS, N. Sobre o tempo. Tradução de Vera Ribeiro. Rio de Janeiro: Jorge Zahar, 1998.

ELIAS, N. Teoria simbólica. 2a ed. Oeiras: Ceuta, 2002.

ELIAS, N.; DUNNING, E. A busca da excitação. Tradução de Maria Manuela Almeida e Silva. Lisboa: Difel, 1992.

ELIAS, N; SCOTSON, J. L. Os Estabelecidos e os Outsiders: sociologia das relações de poder a partir de uma pequena comunidade. Tradução de Vera Ribeiro. Rio de Janeiro: Jorge Zahar Editor, 2000 .

ELIAS, Norbert. A Sociedade dos Indivíduos. Rio de Janeiro: Jorge Zahar, 1994a.

ELIAS, Norbert. Os Alemães. Rio de Janeiro: Jorge Zahar, 1997.

ELIAS, Norbert. Sobre os Seres Humanos e suas Emoções: um ensaio sob a perspectiva da sociologia dos processos. In: GEBARA, Ademir; WOUTERS, Cas. O Controle das Emoções. João Pessoa: Editora da UFPB, 2009. P. 19-46.

ELIAS, Norbert. A Civilização dos Pais. Revista Sociedade e Estado, Brasília, v.27, n. 3, p. 469493, set./dez. 2012. 
Revista Tópicos Educacionais

Revista do Programa de Pós-Graduação em Educação

da Universidade Federal de Pernambuco (UFPE)

Recebido em fevereiro de 2021.

Aprovado em maio de 2021.

Revista Tópicos Educacionais, Pernambuco, v. 27, n.01, p. 210-219, 2021. ISSN: 2448-0215.

https://periodicos.ufpe.br/revistas/topicoseducacionais/index 